\title{
Deterioration of Congestive Heart Failure after Converting to VOO Mode from DDD Mode in a Dilated Cardiomyopathy Patient; Importance of Atrial Contribution
}

\author{
Kanji Iga, Kenjiro Hori, Tadashi Matsumura and Hiromitsu Gen
}

\begin{abstract}
We describe a 62-year-old dilated cardiomyopathy patient in whom congestive heart failure progressed shortly after DDD mode was changed to VOO mode because of battery exhaustion. Emergency battery exchange with restoration of DDD mode improved his functional status to the previous level; pulmonary capillary wedge pressure decreased from 28 to $24 \mathrm{mmHg}$ and cardiac output increased from 1.5 to $2.0 \mathrm{~L} / \mathrm{min}$ associated with widening of the aortic pulse pressure. Maintenance of atrial contraction is therefore important even if left ventricular systolic function is markedly impaired and left ventricular end-diastolic pressure is increased.
\end{abstract}

(Internal Medicine 32: 459-461, 1993)

Key words: DDD pacing, refractory congestive heart failure, systolic dysfunction, Doppler echocardiography

\section{Introduction}

We report rapid progression of congestive heart failure (CHF) after DDD mode was changed to VOO mode because of battery exhaustion in a 62-year-old dilated cardiomyopathy (DCM) patient. We emphasize the importance of the atrial contribution to left ventricular filling even in severe congestive heart failure due to left ventricular systolic dysfunction.

\section{Case Report}

The patient was a 62-year-old male in whom a DDD pacemaker (rate set: $60 / \mathrm{min}$ ) had been implanted 4 years previously because of sick sinus syndrome with poor left ventricular contraction. Pulmonary capillary wedge (PCW) pressure was 6 $\mathrm{mmHg}$, pulmonary artery (PA) pressure $23 / 7 \mathrm{mmHg}$, and cardiac output (CO) $3.0 \mathrm{~L} / \mathrm{min}$. On left ventriculography, the end-diastolic volume of the left ventricle was $294 \mathrm{ml}$ and ejection fraction was $17 \%$. Chest $\mathrm{X}$-ray revealed marked cardiomegaly with left ventricular predominance (cardiothoracic ratio: 60\%). His functional class was New York Heart Association Class III. Symptoms of CHF progressed gradually over the next 4 years.

Overt CHF developed rapidly accompanied by the symptoms of orthopnea and paroxysmal nocturnal dyspnea during the course of one week, and he was admitted to our hospital. The patient was acutely ill and orthopneic associated with cold sweating. Blood pressure was $72 / 50 \mathrm{mmHg}$ and pulse rate was $65 / \mathrm{min}$. Electrocardiography revealed ventricular pacing at the rate of $65 / \mathrm{min}$, differing from that of the DDD mode $(60 / \mathrm{min})$, which is a warning signal indicating battery exhaustion of DDD pacemaker.

Two-dimensional echocardiography revealed the left ventricular diastolic dimension to be $85 \mathrm{~mm}$, the left ventricular systolic dimension $80 \mathrm{~mm}$ and left atrial dimension $40 \mathrm{~mm}$. Color Doppler echocardiography revealed severe mitral regurgitation signal. Transmitral flow velocity by echo Doppler showed the E wave to be $75 \mathrm{~cm} / \mathrm{sec}$; the A wave was $60 \mathrm{~cm} / \mathrm{sec}$ when his own P wave was seen in late diastole (Fig. 1).

Right-side cardiac catheterization disclosed that the right atrial pressure was $12 \mathrm{mmHg}$, PA pressure $45 / 23 \mathrm{mmHg}$, PCW pressure $28 \mathrm{mmHg}$, and aortic pressure $72 / 50 \mathrm{mmHg}$. Cardiac output was $1.5 \mathrm{~L} / \mathrm{min}$. Following emergency battery exchange on the same day, the DDD mode functioned again. PCW pressure decreased from 28 to $24 \mathrm{mmHg}$ and $\mathrm{CO}$ increased to $2.0 \mathrm{~L} / \mathrm{min}$ associated with widening of the aortic pulse pressure range.

His symptoms improved markedly, and the paroxysmal nocturnal dyspnea and orthopnea disappeared. Hemodynamic parameters were measured on the same day 10 minutes after

From the Department of Cardiology, Tenri Hospital, Tenri

Received for publication October 23, 1992; Accepted for publication April 19, 1993

Reprint requests should be addressed to Dr. Kanji Iga, the Department of Cardiology, Tenri Hospital, 200 Mishimacho, Tenri, 632, Japan 

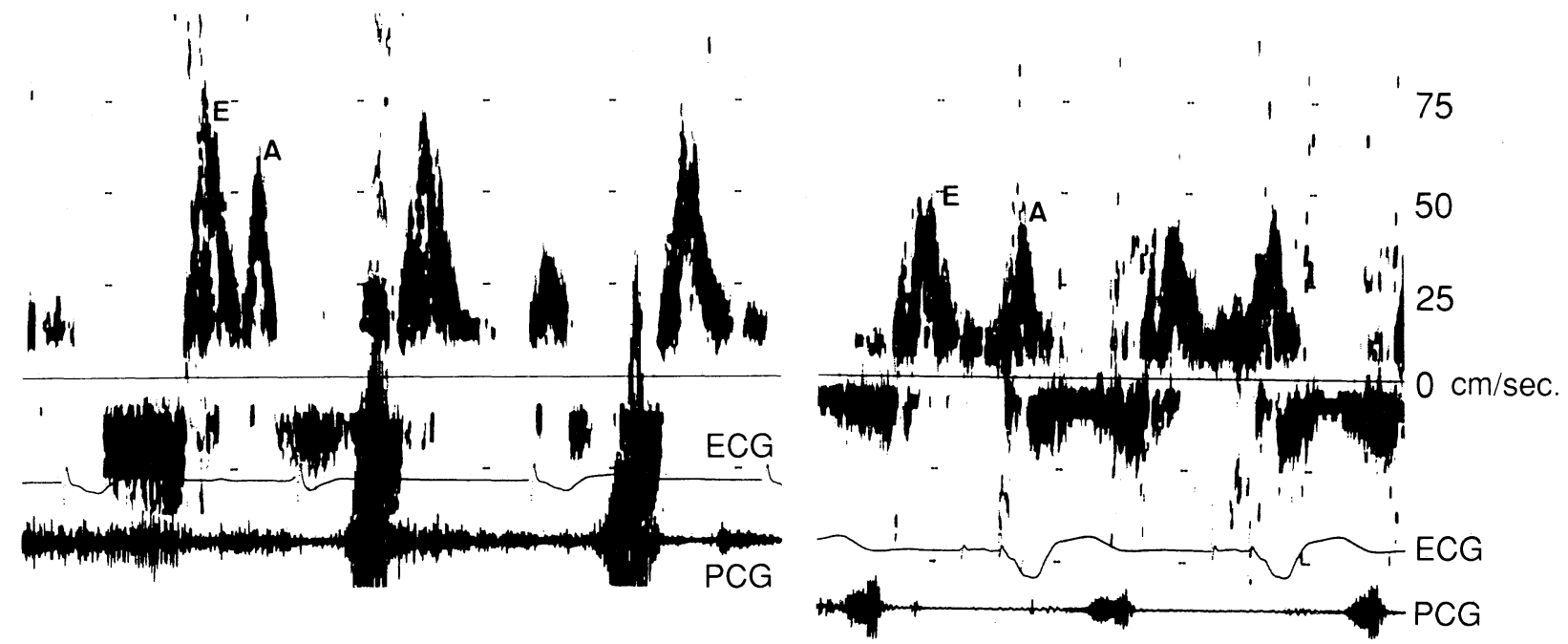

Fig. 1. Echo Doppler study of transmitral flow velocity revealed the A wave to be as high as $60 \mathrm{~cm} / \mathrm{sec}$ when his own $P$ wave was seen in late diastole (first beat in the left). After restoration of DDD function (right), A/E was nearly 1. Pacemaker mode was VOO in the left panel while DDD mode in the right panel. PCG: phonocardiogram, ECG: electrocardiogram.

conversion to VOO mode at a rate of $60 / \mathrm{min}$. CO decreased from 1.9 to $1.5 \mathrm{~L} / \mathrm{min}$ and $\mathrm{PCW}$ increased from 22 to $24 \mathrm{mmHg}$. PA pressure also increased and the pulse pressure range of the femoral artery decreased (Table 1). Over the following two days, $\mathrm{PCW}$ and PA pressures decreased to 12 and $23 / 13 \mathrm{mmHg}$, respectively, and his functional status returned to the previous level. Ten days after battery exchange, left ventricular dimension and left atrial dimension by echocardiography were unchanged (Fig. 2), however signal of mitral regurgitation became less severe. The E wave became $50 \mathrm{~cm} / \mathrm{sec}$ and A wave $50 \mathrm{~cm} /$ sec resulting in an $\mathrm{A} / \mathrm{E}$ ratio of 1 (Fig. 1). Two years later, he died of refractory CHF, however, the DDD pacemaker had been functioning well, the A wave was $37 \mathrm{~cm} / \mathrm{sec}$, and the left atrial size was unchanged just before his death.
Table 1. Comparative Hemodynamic Data during DDD Mode and VVI Mode at the Rate of $60 / \mathrm{min}$

\begin{tabular}{lrcccr}
\hline & RA & PA & PCW & CO & FA \\
\hline DDD mode & 9 & $36 / 22$ & 22 & 1.93 & $104 / 56$ \\
VVI mode & 10 & $44 / 24$ & 24 & 1.52 & $94 / 56$ \\
\hline
\end{tabular}

RA: right atrium $(\mathrm{mmHg})$, PA: pulmonary artery $(\mathrm{mmHg}), \mathrm{PCW}$ : pulmonary capillary wedge $(\mathrm{mmHg}), \mathrm{CO}$ : cardiac output $(\mathrm{L} / \mathrm{min}), \mathrm{FA}$ : femoral artery $(\mathrm{mmHg})$.

\section{Discussion}

Atrial contraction contributes about $15 \%$ of the volume of

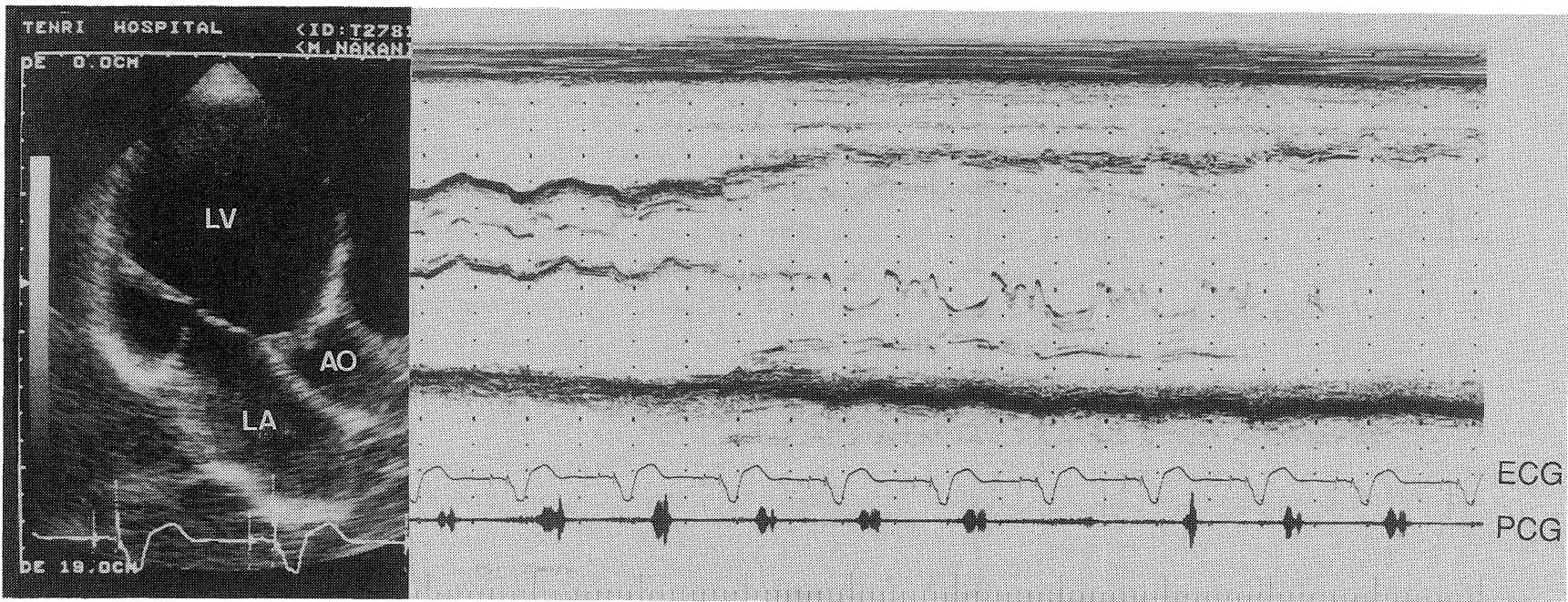

Fig. 2. End-diastolic still frame of apical view shows markedly enlarged left ventricle with thinning of the left ventricular wall (left). LA: left atrium, LV: left ventricle, AO: aorta. M-mode scan echo showed markedly reduced shortening of left ventricle (right). 
left ventricular filling in normal subjects, but approximately $35 \%$ when the left ventricle has become stiff (1). Therefore, preservation of atrial contraction is important in the latter condition. For example, loss of atrial contraction due to transient atrial fibrillation can cause CHF in hypertrophic cardiomyopathy patients. Generally speaking, however, when left ventricular end-diastolic pressure is markedly increased, atrial contraction no longer contributes to left ventricular filling (2). Maintenance of sinus rhythm under this situation is not for the purpose of preservation of atrial contraction in left ventricular filling but to control the heart rate.

Recent development of the sophisticated VVI pacemaker enables determination of heart rate during exercise by sensing vibration of the body or generation of the heat in the skin. This VVI-R mode (rate responsive mode) has become commonly used because insertion of only one lead is adequate while DDD pacing requires two leads. DDD pacing is more physiologically integrated than VVI pacing, but VVI-R mode presents no problems in those patients with normal left ventricular function.

In the present patient, left ventricular cavity was markedly increased with slight increased left atrial cavity and loss of atrial contraction due to battery exhaustion resulting in severe CHF. After restoration of physiological atrioventricular sequence, CHF improved together with a slight decrease in $\mathrm{PCW}$ pressure, an increase in $\mathrm{CO}$ and widened aortic pulse pressure range. Hemodynamic study on the same day at the same heart rate showed that, in VOO mode, CO decreased $21 \%$ with a slightly increased PCW pressure. The pulse pressure of the femoral artery decreased. Two days after restoration of DDD mode, PCW and PA pressures decreased, and the functional status improved markedly. It was evident that restoration of atrial contraction was quite useful in improving $\mathrm{CHF}$ in this patient.

Transmitral flow velocity pattern by echo Doppler showed that the $\mathrm{A} / \mathrm{E}$ ratio increased on relaxation abnormality pattern and decreased on restrictive filling pattern (3). The latter is known as pseudonormalization of the $\mathrm{A} / \mathrm{E}$ ratio (4) and the $\mathrm{A}$ wave is barely seen in severe CHF.

When his $\mathrm{P}$ wave was seen in the diastole in this $\mathrm{CHF}$, the $\mathrm{A}$ wave was $60 \mathrm{~cm} / \mathrm{sec}$ although PCW pressure was as high as 28 $\mathrm{mmHg}$. The E wave decreased from $75 \mathrm{~cm} / \mathrm{sec}$ to $50 \mathrm{~cm} / \mathrm{sec}$ after improvement of $\mathrm{CHF}$ which can be explained by concomitant less severe mitral regurgitation (4). As the size of the left atrium was $40 \mathrm{~mm}$ by echocardiography and was not markedly increased until his death, this relatively small left atrium as visualized by two-dimensional echocardiography was able to generate atrial contraction against the increased left ventricular end-diastolic pressure. This might be the reason why restoration of atrial contraction markedly improved this CHF.

Therefore, even if left ventricular end-diastolic pressure is increased enough to induce severe CHF due to left ventricular systolic dysfunction, maintenance of sinus rhythm deserves consideration.

\section{References}

1) Rahimtola SH, Ehsani A, Sinno MZ, et al. Left atrial transport function in myocardial infarction: Importance of its booster function. Am J Med 59: 686, 1975.

2) Greenberg B, Chatterjee K, Parmely WM, et al. The influence of left ventricular filling pressure on atrial contribution to cardiac output. Am Heart J 98: 742, 1979.

3) Nishimura RA, Abel MD, Hatle LK, et al. Assessment of diastolic function of the heart: Background and current applications of Doppler Echocardiography. Mayo Clin Proc 64: 181, 1989.

4) Iga $\mathrm{K}$, Hori $\mathrm{K}$, Matsumura $\mathrm{T}$, et al. Left ventricular filling pattern in congestive heart failure patients with normal sinus rhythm; A decreased ratio of peak mitral flow velocity in atrial systole relative to that in early diastole may reflect markedly increased left ventricular end-diastolic pressure. Jpn Cir J 54: 473, 1990. 